\title{
Esters of (S)-1,2-propanediol and (R,R)-2,3-butanediol - Chiral Compounds Inducing Cholesteric Phases with a Helix Inversion •
}

\author{
G. Heppke, D. Lötzsch, and F. Oestreicher \\ Technische Universität Berlin -ER 11-, Berlin \\ Z. Naturforsch. 42 a, 279-283 (1987); received November 12, 1986 \\ Mesogenic chiral esters of optically active (S)-1,2-propanediol and (R,R)-2,3-butanediol were \\ synthesized. The compounds, added to a nematic phase induce cholesteric phases exhibiting a \\ helix inversion with temperature variation. This effect is independent of the molecular structure \\ of the nematic solvent. The inversion temperature varies only slightly with concentration but can \\ be influenced by the mesogenic substituent.
}

\section{Introduction}

The helical structure of cholesteric liquid crystals is based on the chiral molecular structure [1]. Enantiomers produce cholesteric helices of opposite sense. Thus, a helix inversion induced by temperature variation, i.e. the forming of a nematic structure at a certain temperature may not be expected at first sight.

However, this phenomenon was found in compensated cholesteric mixtures consisting of cholesteryl derivatives where at a certain composition a nematic phase appears [2-4]. The same is observed also in mixtures consisting of one cholesteryl derivative and a nematic phase [5-7]. In these systems the effect depends strongly on the concentration of the components and hence the helix inversion temperature is very sensitive to composition. Similar behaviour has been observed in induced cholesteric systems with two chiral dopants exhibiting different temperature dependence of the helical twisting power $[8,9]$.

In this paper results on new chiral dopants are reported which induce cholesteric phases with unusual temperature dependence of the helical pitch. Even though the induced cholesteric phases contain only one chiral dopant and in the case of some dopants only one chiral centre, the systems studied exhibit a helix inversion at a certain temperature

\footnotetext{
* Presented in part at the $10^{\text {th }}$ International Liquid Crystal
} Conference, York, England, July 1984.

Reprint requests to Prof. Dr. G. Heppke, Technische Universität Berlin -ER11-, Straße des 17. Juni 135, D-1000 Berlin 12. which is nearly independent of the concentration of the chiral compound.

\section{Experimental}

The new chiral dopants are diesters of the optically active (S)-1,2-propanediol or (R,R)-2,3-butanediol with mesogenic carboxylic acids.

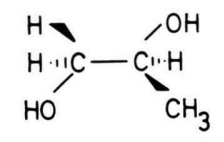

(S)-1,2 - propanediol

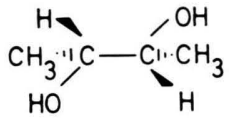

$(R, R)-2,3$-butanediol
The compounds were synthesized by interacting $12 \mathrm{mmol}$ of the relevant acid chloride and $5 \mathrm{mmol}$ optically active dialcohol in $20 \mathrm{~cm}^{3}$ pyridine. Purification was achieved by chromatography on a column of silica gel with methylene chloride and recrystallisation in isopropyl alcohol. The structures and transition temperatures are given in Table 1.

The twisting power of the synthesized esters was investigated using the nematic wide range mixtures RO-TN $404\left[t_{\mathrm{NI}}=105^{\circ} \mathrm{C}\right]$ Hoffmann-La Roche, $\mathrm{S} 1132\left[t_{\mathrm{NI}}=71^{\circ} \mathrm{C}\right]$ Merck, ZLI $1275\left[t_{\mathrm{NI}}=83^{\circ} \mathrm{C}\right]$ Merck and the single component liquid crystals heptylcyanobiphenyle $(7 \mathrm{CBP})\left[t_{\mathrm{NI}}=43^{\circ} \mathrm{C}\right] \mathrm{BDH}$ and ethyloxybenzylidenebutylaniline $(\mathrm{EBBA})\left[t_{\mathrm{NI}}=\right.$ $\left.79^{\circ} \mathrm{C}\right]$ Riedel de Haën AG.

The pitch $p$ and the helical screw sense of the induced cholesteric phases were determined by the modified Grandjean-Cano-method [10-13].

To characterize the twisting power of the induced cholesteric systems either the product $p c$ ( $c$ is the

0340-4811 / 87 / 0300-0279 \$01.30/0. - Please order a reprint rather than making your own copy. 
Table 1. Structure, configuration and transition temperatures of the synthesized mesogenic esters of (S)-1,2-propanediol and (R,R)-2,3-butanediol. The temperature $t_{\mathrm{c}}$ is the virtual clearing point, extrapolated from mixtures with the nematic phase RO-TN 404.

\begin{tabular}{|c|c|c|c|c|}
\hline No. & Configuration & Structure & Transition temperatures & ${ }^{t_{c}} /{ }^{\circ} \mathrm{C}$ \\
\hline la & $\mathrm{S}$ & $\mathrm{C}_{6} \mathrm{H}_{13}-\mathrm{O}-(0)-\mathrm{COO}$ 上 $\mathrm{OOC}-\left(0-0-\mathrm{C}_{6} \mathrm{H}_{13}\right.$ & Cr. 351 & -60 \\
\hline $1 b$ & $\mathrm{~S}$ & $\mathrm{C}_{6} \mathrm{H}_{13}-\mathrm{O}-(0)-\mathrm{COO}-(0)-\mathrm{COO}$ 人 $\mathrm{OOC}-(0)-0 \mathrm{C}-(0)-0-\mathrm{C}_{6} \mathrm{H}_{13}$ & Cr. $130 \mathrm{~S}(126) \mathrm{I}$ & \\
\hline le & $\mathrm{S}$ & $\mathrm{C}_{7} \mathrm{H}_{15}-\mathrm{H}-\mathrm{O}-\mathrm{COO}$ 上 $\mathrm{OOC}-\mathrm{O}-\mathrm{O}-\mathrm{C}_{7} \mathrm{H}_{15}$ & Cr.93 I & 53 \\
\hline $1 f$ & $\mathrm{~S}$ & 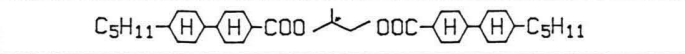 & Cr. $162 \mathrm{I}$ & 80 \\
\hline $\mathrm{g}$ & $\mathrm{S}$ & 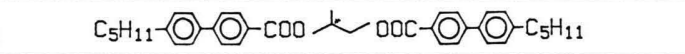 & Cr. $118 \mathrm{I}$ & 53 \\
\hline $2 a$ & $R, R$ & $\mathrm{C}_{6} \mathrm{H}_{13}-\mathrm{O}-(\mathrm{O})-\mathrm{COO}+\mathrm{N}, \mathrm{OOC}-(\mathrm{O})-\mathrm{O}-\mathrm{C}_{6} \mathrm{H}_{13}$ & Cr. 531 & -- \\
\hline $2 b$ & $R, R$ & $\mathrm{C}_{6} \mathrm{H}_{13}-\mathrm{O}-(0)-\mathrm{COO}-(0)-\mathrm{COO}+\mathrm{C}_{1} \mathrm{OOC}-(0)-00 \mathrm{C}-(0)-0-\mathrm{C}_{6} \mathrm{H}_{13}$ & Cr. 133 I & 87 \\
\hline $2 c$ & $R, R$ & $\mathrm{C}_{5} \mathrm{H}_{11}-\mathrm{H}-\mathrm{O}-\mathrm{COO}$ 人 $\mathrm{OOC}-\mathrm{O}-\mathrm{O}-\mathrm{H}-\mathrm{C}_{5} \mathrm{H}_{11}$ & Cr. 1381 & 28 \\
\hline $2 d$ & $R, R$ & $\mathrm{C}_{5} \mathrm{H}_{11}-\mathrm{H}-\mathrm{O}-\mathrm{O}-\mathrm{O}-\mathrm{COO}+\mathrm{OOC}-\mathrm{O}-\left(\mathrm{O}-\mathrm{H}-\mathrm{C}_{5} \mathrm{H}_{11}\right.$ & Cr. 212 S (197) N"255 I & \\
\hline $2 e$ & $R, R$ & $\mathrm{C}_{7} \mathrm{H}_{15}-\mathrm{H}-\mathrm{O}-\mathrm{O}-\mathrm{COO}+\mathrm{O} \mathrm{OOC}-\mathrm{O}-\mathrm{H}-\mathrm{C}_{7} \mathrm{H}_{15}$ & Cr.112I & 40 \\
\hline $2 f$ & $R, R$ & 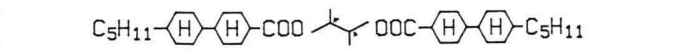 & Cr.180I & 63 \\
\hline
\end{tabular}

concentration of the chiral additive in wt. $\%$ ) or the molecular twisting power $\beta=1 / p N_{\mathrm{V}}$ was used $\left(N_{\mathrm{V}}\right.$ is the number density of the chiral dopant in mol/ $\mathrm{m}^{3}$ ). The values of $\beta$ were calculated assuming a density of the liquid crystalline solution of $1 \mathrm{~g} / \mathrm{cm}^{3}$.

\section{Results and Discussion}

To demonstrate the phenomenon of the helix inversion induced by the new chiral dopants the temperature dependence of the $p c$-product of a solution of $1.2 \mathrm{wt} .-\%$ of the propanediol derivative $\mathbf{1} \mathbf{b}$ in the nematic wide range mixture RO-TN 404 is shown in Figure 1 . At $20^{\circ} \mathrm{C}$ the $p c$-product is about $-45 \mu \mathrm{m}$ wt. $-\%$. Generally in cholesteric phases induced by nematic-like chiral molecules the pitch was found to increase with $10^{-3}$ to $10^{-2} \mathrm{~K}^{-1}[14,15]$, whereas the magnitude of the pitch of compound $\mathbf{1 b}$ in RO-TN 404 shows a much stronger increase with temperature, resulting in a divergence at about $70{ }^{\circ} \mathrm{C}$. At this inversion temperature the helical structure changes from lefthanded to righthanded and above this temperature the magnitude of the pitch decreases strongly.

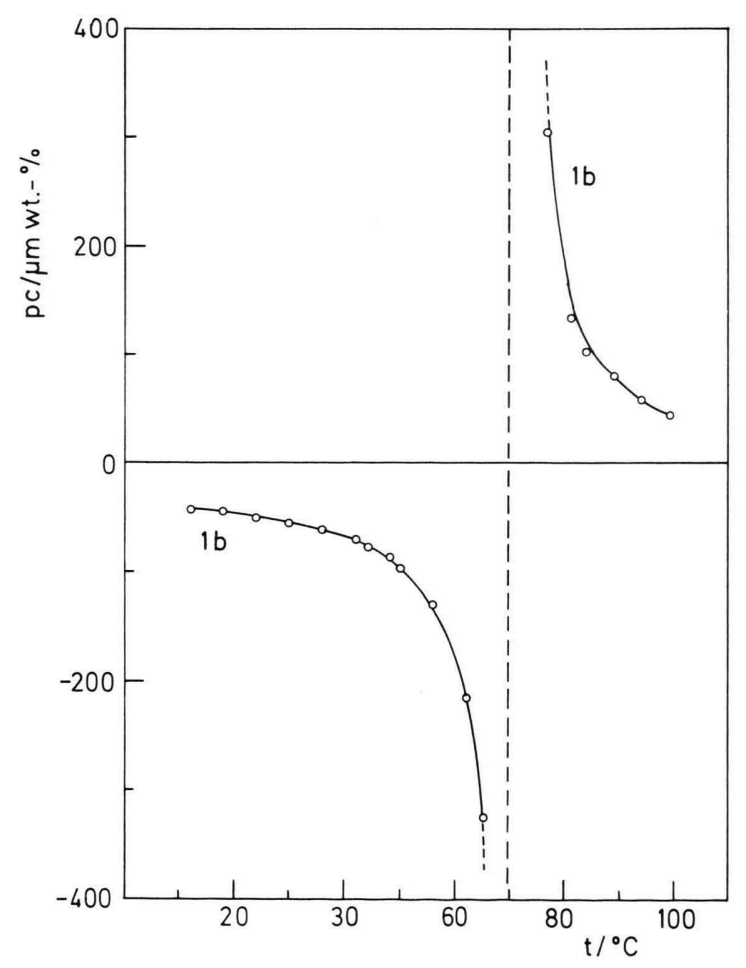

Fig. 1. Temperature dependence of the $p c$-product of compound 1b in RO-TN $404(c=1.2 \mathrm{wt} .-\%)$. The helix inversion of the induced cholesteric structure occurs at $70{ }^{\circ} \mathrm{C}$. 


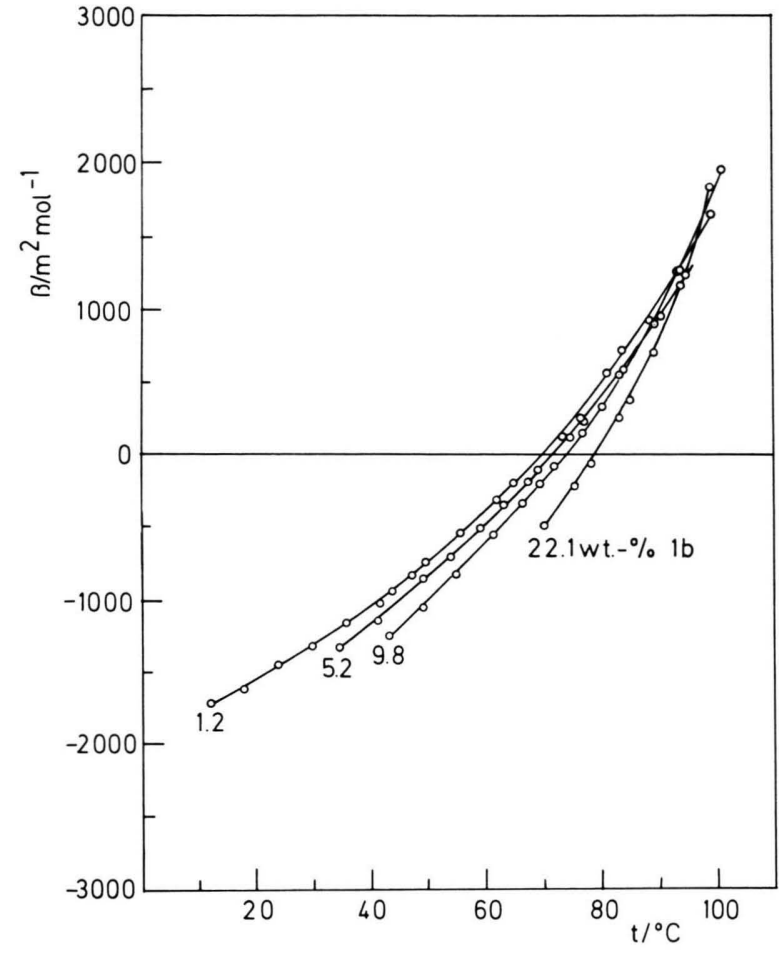

Fig. 2. Temperature dependence of the molecular twisting power $\beta$ of compound $\mathbf{1 b}$ in RO-TN 404 at different concentrations of the chiral additive.

The temperature dependence of the corresponding molecular twisting power $\beta$ of compound $\mathbf{1} \mathbf{b}$ in RO-TN 404 is shown in Fig. 2 for different concentrations (1.2, 5.2, 9.8 and $22.1 \mathrm{wt} . \mathrm{\%})$. Although there is a variation in the slope of the $\beta$ curve the helix inversion temperature varies only by about $10 \mathrm{~K}$ in the investigated concentration range, whereas the clearing temperature is nearly constant. The fact that the helix inversion is maintained even at high concentrations leads to the assumption that it is caused by a property of the chiral dopant. To corroborate this assumption the molecular twisting power of $\mathbf{1} \mathbf{b}$ was investigated in different nematic solvents (Figure 3). In all investigated nematic phases, the chiral dopant $\mathbf{1} \mathbf{b}$ produces a helix inversion in the mesophase temperature region, though the clearing temperatures differ considerably. This indicates an influence of the nematic order on the effect. The appearance of the helix inversion in the single compound nematic phases ethyloxybenzylidenebutylaniline (EBBA) and heptylcyanobiphenyle (7 CBP) contradicts the argument that in the multi-

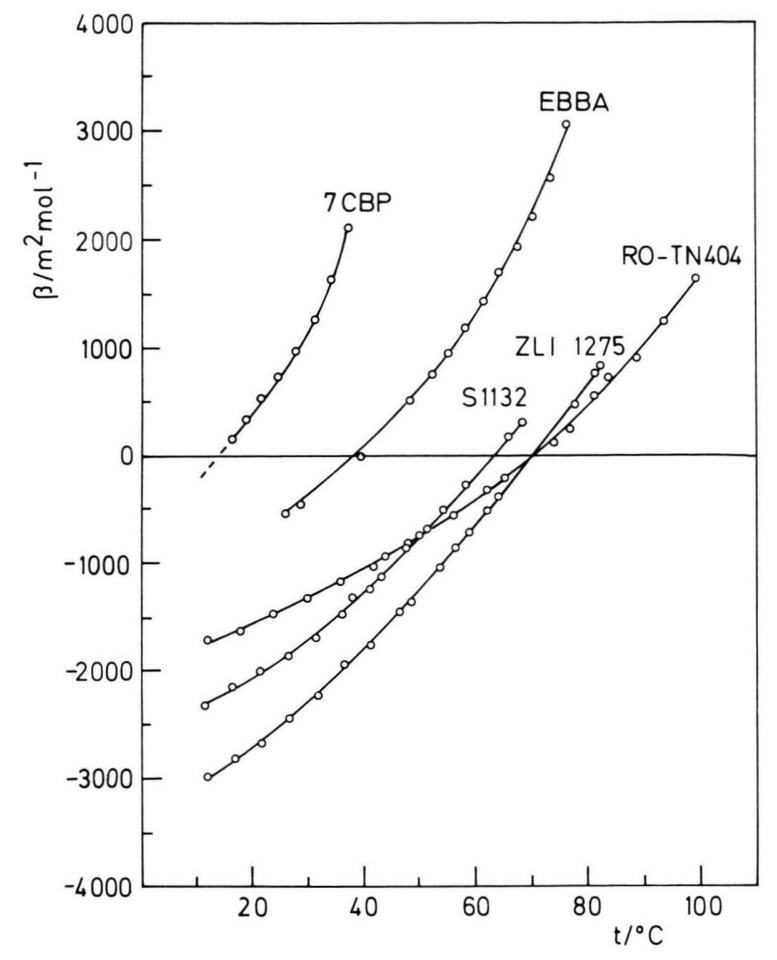

Fig. 3. Temperature dependence of the molecular twisting power $\beta$ of compound $\mathbf{1} \mathbf{b}$ in different nematic phases. The concentrations of $\mathbf{1 b}$ were $1.2 \mathrm{wt} .-\%$ in RO-TN 404, 1.0 wt. $-\%$ in S1132, 1.0 wt.- $\%$ in ZLI1275, 1.1 wt.- $\%$ in EBBA and 1.5 wt.- $\%$ in 7 CBP. The helix inversion in $7 \mathrm{CBP}$ was observed microscopically.

component mixtures several molecular complexes with opposite sign of the molecular twisting power may exist, which change their relative amount with temperature thereby producing a helix inversion.

In order to compare the temperature dependence of the molecular twisting power of all the synthesized chiral dopants, the multicomponent mixture ROTN 404 was chosen as a nematic solvent because of its wide temperature range. As shown in Fig. 4 all derivatives of 1,2-propanediol exhibit a similar temperature dependence of the induced helical structure, i.e. increasing $\beta$ with increasing temperature, though the inversion temperature strongly depends on the choice of the mesogenic substituents. For compound 1 a the extrapolated inversion temperature of $130^{\circ} \mathrm{C}$ is well above the clearing temperature of the cholesteric mixture $\left(104^{\circ} \mathrm{C}\right)$.

In order to vary the chiral middle group a second series of compounds was synthesized with $(R, R)$ 2,3-butanediol, where a methyl group replaces a 


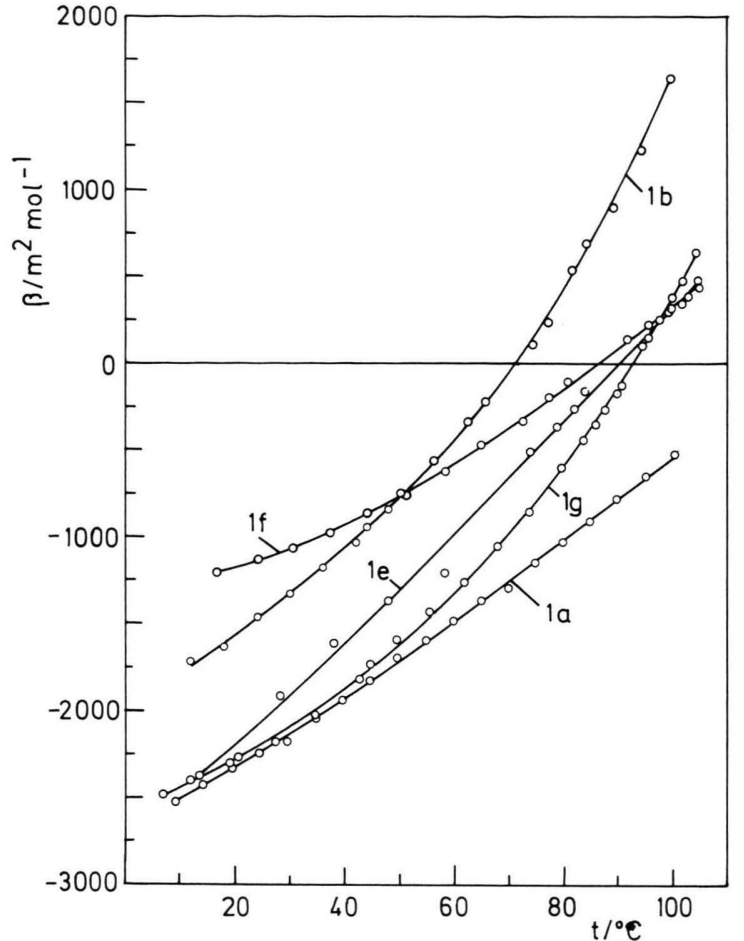

Fig. 4. Temperature dependence of the molecular twisting power $\beta$ of the esters of (S)-1,2-propanediol in RO-TN 404.

hydrogen atom of the (R)-1,2-propanediol, thereby introducing a second chiral centre. Due to the opposite absolute configuration of the two chiral alcohols, which were used for the synthesis, the curves show different signs of the slopes (Figures 4, 5). Taking this into account the temperature dependence of the molecular twisting power is very similar. Compounds $\mathbf{2 b}, \mathbf{2 c}, \mathbf{2 d}$ and $\mathbf{2 e}$ show a helix inversion at about $60^{\circ} \mathrm{C}$. For $2 \mathrm{a}$ the $\beta$ curve can be extrapolated to a virtual helix inversion temperature of about $145^{\circ} \mathrm{C}$. Only for the pentylcyclohexylcyclohexane derivatives $1 \mathbf{f}$ and $\mathbf{2} \mathbf{f}$, the temperature dependence differs considerably between the propanediol and the butanediol middle group.

An explanation of the helix inversion in the systems described is not yet possible. Since it can be excluded that the absolute configuration changes with temperature, the basic mechanism might be a change in the conformation of the chiral molecule. Earlier investigations have shown that the sign of the pitch induced by mesogenic chiral compounds

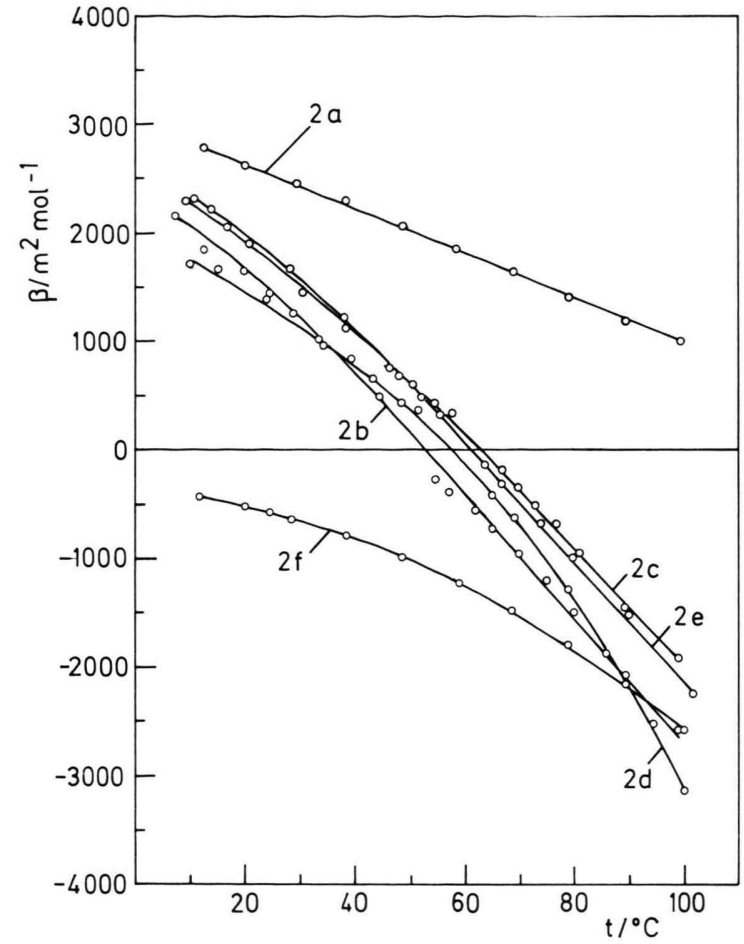

Fig. 5. Temperature dependence of the molecular twisting power $\beta$ of the esters of $(\mathrm{R}, \mathrm{R})-2,3$-butanediol in RO-TN 404.

depends not only on the absolute configuration but also on the orientation of the chiral centre with respect to the molecular long axis [16]. This is not only demonstrated by the odd-even-rule $[12,17]$ but also by the helix inversion occurring at the change from cis to trans isomers of ortho substituted optically active dialkylazobenzenes $[18,19]$. Consequently, in order to explain the helix inversion of the compounds investigated here, the assumption of a conformation change should be taken into account. If the conformeres induce cholesteric structures of opposite screw sense and if the ratio of the conformeres depends on temperature, the helix inversion may appear.

As Table 1 shows two of the compounds are found to exhibit liquid crystalline phases. In the case of $\mathbf{1} \mathbf{b}$ only a smectic phase appears. Compound $\mathbf{2} \mathbf{d}$ shows a cholesteric phase at very high temperature, which did not allow to measure the pitch of the pure compound with the experimental setup. A pure compound with helix inversion has not yet 
been found [20 in connection with 21], but from the present results it can be expected that by appropriate variation of the mesogenic substituents in this new class of chiral compounds the realisation should be possible.

[1] G. Solladié and R. G. Zimmermann, Angew. Chem. 96, 335 (1984).

[2] H. Baessler, Festkörperprobleme 11, 99 (1971).

[3] H. Baessler and M. M. Labes, J. Chem. Phys. 52, 631 (1970).

[4] H. Stegemeyer, Ber. Bunsenges. Phys. Chem. 78, 860 (1974).

[5] F. D. Saeva and J. J. Wysocki, J. Amer. Chem. Soc. 93, 5928 (1971).

[6] H. Finkelmann and H. Stegemeyer, Z. Naturforsch. 28a, 799 (1973).

[7] K. Siemensmeyer and H. Stegemeyer, 11th International Liquid Crystal Conference, Berkeley, USA, 1986 , Poster $\Theta-048-\mathrm{CH}$

[8] A. Göbl-Wunsch and G. Heppke, Z. Naturforsch. 34 a, 594 (1979).

[9] A. Göbl-Wunsch, G. Heppke, and F. Oestreicher, J. Phys. Paris 40, 773 (1979).

[10] F. Grandjean, C. R. Acad. Sci. Paris 172, 71 (1921).

[11] R. Cano, Bull. Soc. Franc. Mineral. Crist. 90, 333 (1967).
Acknowledgement

The authors would like to thank the Deutsche Forschungsgemeinschaft for financial support and E. Merck and Hoffmann-La Roche for supplying them with intermediates and nematic liquid crystals.

[12] G. Heppke and F. Oestreicher, Z. Naturforsch. 32a, 899 (1977).

[13] G. Heppke and F. Oestreicher, Mol. Cryst. Liq. Cryst. 41 (Letters), 245 (1978).

[14] F. Oestreicher, Thesis, Berlin 1984

[15] H. Stegemeyer and H. Finkelmann, Naturwiss. 62, $436(1975)$

[16] B. W. Van der Meer and G. Vertogen, Z. Naturforsch. 34 a, 1359 (1979).

[17] G. W. Gray and D. G. McDonnell, Mol. Cryst. Liq. Cryst. 34 (Letters), 211 (1977).

[18] G. Heppke, H. Marschall, P. Nürnberg, F. Oestreicher, and G. Scherowsky, Chem. Ber. 114, 2501 (1981).

[19] G. Heppke, F. Oestreicher, and G. Scherowsky, Z. Naturforsch. 37 a, 1167 (1982).

[20] G. Durand, C. R. Acad. Sci. Paris 264 B, 1251 (1967)

[21] H. Baessler, P. A. Malya, W. R. Nes, and M. M. Labes, Mol. Cryst. Liq. Cryst. 6, 329 (1970). 